\title{
SUSTAINED BENEFIT LASTING ONE YEAR FROM T4 INSTEAD OF T3-T4 SYMPATHECTOMY FOR ISOLATED AXILLARY HYPERHIDROSIS
}

\author{
Marco Antonio S. Munia, Nelson Wolosker, Paulo Kaufmann, José Ribas \\ Milanes de Campos, Pedro Puech-Leão
}

doi: $10.1590 / \mathrm{S} 1807-59322008000600011$

Munia MAS, Wolosker N, Kaufmann P, Milanez de Campos JR, Puech-Leão P. Sustained benefit lasting one year from T4 instead of T3-T4 sympathectomy for isolated axillary hyperhidrosis. Clinics. 2008;63:771-4.

INTRODUCTION: Level T4 video-assisted thoracoscopic sympathectomy proved superior to T3-T4 treatment for controlling axillary hyperhidrosis at the initial and six-month follow-ups of these patients.

OBJECTIVE: To compare the results of two levels of sympathectomy (T3-T4 vs. T4) for treating axillary sudoresis over one year of follow-up.

METHODS: Sixty-four patients with axillary hyperhidrosis were randomized to denervation of T3-T4 or T4 alone and followed prospectively. All patients were examined preoperatively and were followed postoperatively for one year. Axillary hyperhidrosis treatment was evaluated, along with the presence, location, and severity of compensatory hyperhidrosis and self-reported quality of life.

RESULTS: According to patient reports after one year, all cases of axillary hyperhidrosis were successfully treated by surgery. There were no instances of treatment failure. After six months, compensatory hyperhidrosis was present in 27 patients of the T3-T4 group (87.1\%) and in 16 patients of the T4 group (48.5\%). After one year, all T3-T4 patients experienced some degree of compensatory hyperhidrosis, compared to only 14 patients in the T4 group (42.4\%). In addition, compensatory hyperhidrosis was less severe in the T4 patients $(\mathrm{p}<0.01)$. Quality of life was poor before surgery, and it improved in both groups at six months and one year of follow-up $(\mathrm{p}=0.002)$. There were no cases of mortality, no significant postoperative complications, and no need for conversion to thoracotomy in either group.

CONCLUSION: Both techniques were effective for treating axillary hyperhidrosis, but the T4 group showed milder compensatory hyperhidrosis and greater patient satisfaction at the one-year follow-up.

KEYWORDS: Hyperhidrosis; Axillary; Compensatory hyperhidrosis; Sudoresis; Sympathectomy.

\section{INTRODUCTION}

Axillary hyperhidrosis is an important disease that may cause serious emotional and work-related problems. Local treatment and psychotherapy show low effectiveness. Injections of botulinum toxin offer good but temporary results lasting fewer than six months, and excision/resection

Hospital das Clínicas, Faculdade de Medicina, Universidade de São Paulo - São Paulo/SP, Brazil

Email: ma.munia@uol.com.br

Tel.: 55113078.4104

Received for publication on June 10, 2008

Accepted for publication on September 1, 2008 of the eccrine sweat glands is less effective and allows for a higher recurrence rate than sympathectomy. ${ }^{1-5}$

Video-assisted thoracic sympathectomy (VATS) is a recognized procedure for the definitive treatment of palmar hyperhidrosis, but its efficacy in treating axillary hyperhidrosis remains controversial. No randomized, prospective studies of axillary hyperhidrosis treatment have been published that compare different levels of thermoablation of the sympathetic chain in VATS.

Therefore, we carried out a randomized, prospective study to compare the results of VATS at two resection levels, T3T4 versus T4. Efficacy of axillary hyperhidrosis treatment, presence and severity of compensatory hyperhidrosis, and patient satisfaction were evaluated over one year 
after the surgery using an interview and a quality-of-life questionnaire.

\section{METHODS}

After randomization, 64 patients with pure axillary hyperhidrosis, ranging in age from 17 to 46 years, were submitted to VATS. All patients received information regarding risks and chances of compensatory hyperhidrosis. Criteria for inclusion in the study were a complaint of axillary hyperhidrosis and the intention to undergo surgery. Criteria for exclusion were the existence of prior thoracic surgery; the existence of diseases such as cardiac diseases, pulmonary infections, neoplasia, or pleural or lung diseases that could increase surgical risk; or a body mass index (BMI) greater than 25. ${ }^{6,7}$

All patients were submitted to surgery under general anesthesia with selective intubation and pulmonary ventilation. Two incisions were made in each hemithorax: the first at the fourth intercostal space on the anterior axillary line, and the second at the third intercostal space on the mid-axillary line. ${ }^{8,9}$

After identification of each sympathetic chain, patients randomized into the T3-T4 group underwent sympathicotomy on the bodies of the third, fourth, and fifth ribs, followed by thermoablation of the segments isolated between them. Patients randomized into the T4 group underwent resection of the chain (sympathicotomy) at the fourth and fifth ribs, with thermoablation of the segment between them. After the sympathectomy, the lung was reexpanded under direct viewing and air was simultaneously aspirated from the pleural space using a small catheter (16 Fr). The same procedure was carried out on the contralateral chain. There was no routine use of a chest drain. A chest $\mathrm{x}$-ray was performed following the operation in order to assess lung expansion.

Patients were followed for one year after intervention. At 12 months after the index procedure, systematic reexaminations were performed on all patients. The observers recording the findings were blinded to patients' treatments. The following were assessed:

1. Presence or absence of axillary hyperhidrosis reported by the patient and confirmed by the examiner.

2. Presence or absence of compensatory hyperhidrosis, along with its location and severity, as reported by the patient and confirmed by the examiner. The severity of the sudoresis was graded at one of three levels: mild, moderate, or severe. Patients who noticed no difference in the location or intensity of their body sweat were deemed unaffected by compensatory hyperhidrosis. Mild compensatory sweating was considered present when patients reported minor modifications in the location and severity of their perspiration, such as visible sweating, but did not express significant concern about it. Moderate compensatory hyperhidrosis was considered present when patients reported visible and embarrassing sweating or occasionally disabling situations caused by sweating.

Finally, severe compensatory hyperhidrosis was considered present when patients reported interference in their social and professional activities, such as the need for successive clothing changes caused by sweating of the same intensity as their previous axillary hyperhidrosis, but at other primary locations. It was defined as severe when it was visible, embarrassing, and led to at least one change of clothes during the day.

3. The patients' satisfaction with the final outcome of the procedure (including both the treatment and any complications) was subjectively evaluated using a multiplechoice subjective rating scale (four options): 1 , deficient (dissatisfied); 2 , fair; 3 , very good; 4 , excellent.

\section{STATISTICAL ANALYSIS}

For categorical variables, depending on the sample, the $\chi^{2}$ or Fisher's exact tests were used for verifying associations between the type of surgery and possible results and complications. These statistical tests were used at each follow-up assessment to compare types of surgery with the variables of interest (axillary hyperhidrosis, incidence and severity of compensatory hyperhidrosis, and patient satisfaction). The associations between patients' ages, degrees of satisfaction, and ganglion resection level (T3-T4 or T4) were investigated using the Mann-Whitney U test. Significance for all tests was defined at $5 \%$.

\section{RESULTS}

The mean age and gender distributions in the two groups were similar (Table 1). The incidence and severity of compensatory hyperhidrosis are presented in Table 2 . No recurrence of axillary hyperhidrosis was reported at the 12-month follow-up in either of the groups.

The incidence of compensatory hyperhidrosis was lower in the T4 group, at one month, six months, and 12 months of follow-up. Compensatory hyperhidrosis was less severe in the T4 group, and this group showed no cases of severe compensatory hyperhidrosis by the final follow-up at 12 months.

Table 1 - Clinical characteristics of the patient sample

\begin{tabular}{lccc}
\hline & T3-T4 group & T4 group & p value \\
\hline Mean age & 25.06 & 26.67 & \\
Men/Women & $10 / 21$ & $4 / 29$ & 0.051 \\
\hline
\end{tabular}


Table 2 - Incidence and severity of compensatory hyperhidrosis in the two patient groups following surgery

\begin{tabular}{lcccccc}
\hline Group & \multicolumn{3}{c}{6 months } & \multicolumn{3}{c}{ 1 year } \\
\cline { 2 - 7 } & Absent & Mild & $\begin{array}{c}\text { Moderate/ } \\
\text { Severe }\end{array}$ & Absent & Mild & $\begin{array}{c}\text { Moderate/ } \\
\text { Severe }\end{array}$ \\
\hline T3-T4 & 4 & 16 & 11 & 2 & 18 & 11 \\
T4 & 17 & 14 & 2 & 19 & 13 & 1 \\
& \multicolumn{3}{c}{$\mathrm{p}<0.001 *$} & & $\mathrm{p}<0.001 *$ \\
\hline
\end{tabular}

*Based on the chi-squared test.

Table 3 - Patient satisfaction rates

\begin{tabular}{lcccc}
\hline \multirow{2}{*}{ Group } & \multicolumn{2}{c}{6 months } & \multicolumn{2}{c}{1 year } \\
\cline { 2 - 5 } & Mean Rank & Sum of Ranks & Mean Rank & Sum of Ranks \\
\hline T3-T4 & 26.79 & 830.50 & 26.73 & 828.50 \\
T4 & 37.86 & 1249.50 & 37.92 & 1251.50 \\
& \multicolumn{2}{c}{$0.0002 *$} & \multicolumn{2}{c}{$0.002 *$} \\
\hline
\end{tabular}

*Based on the Mann-Whitney test, using asymptotic two-tailed significance.

The incidence and severity of compensatory hyperhidrosis in patients who underwent T3-T4 resection remained constant over the 12 months of follow-up, whereas both the incidence and severity of compensatory hyperhidrosis decreased in the T4 group from six to 12 months ( $p>0.05)$. There was no difference in the location of compensatory hyperhidrosis between the two groups: the most affected regions were the abdomen, back, and legs. The groups also reported no difference in the situations that triggered the compensatory hyperhidrosis: the majority of patients in both groups (21 in the T3-T4 group, 12 in the T4) attributed it to heat and intense physical activity.

The reports of patient satisfaction are presented in Table 3. Patients of the $\mathrm{T} 4$ group reported higher satisfaction than those of the T3-T4 group $(\mathrm{p}<0.05)$. It should be emphasized that, after one year, none of the patients in the T4 group were dissatisfied, but five patients in the T3-T4 group were dissatisfied.

\section{DISCUSSION}

Despite current local and systemic therapeutic modalities, axillary hyperhidrosis is still a frequent condition that affects a great number of patients, leading to disturbances in social and professional life. ${ }^{2,3,6,10}$

Previous studies have shown that VATS is an effective treatment for axillary hyperhidrosis, with a success rate of $89 \% .^{11,12}$ As a result of technical advances and a procedural change such that resection is carried out at a lower ganglion level (fourth ganglia), the technique now has a success rate of
$94 \% .{ }^{13}$ In the present study, we observed that both T3-T4 and $\mathrm{T} 4$ resections were effective in all cases at both one month and 12 months of follow-up. We attribute this success rate to the extreme care taken in identifying patients who would benefit the most from surgical treatment, and accepting them for treatment only after they had received an adequate explanation of all the risks and of the possibility of compensatory hyperhidrosis and still expressed a desire to undergo surgery. This approach meant that only the patients best suited to the procedure and its aftermath were admitted for treatment.

One problem found in several case series is the degree of recurrent axillary hyperhidrosis, which has been reported to range from $15 \%{ }^{15}$ to $65 \%{ }^{16,17}$ In our study, we did not observe any recurrence in either group at six or 12 months follow-up. This lack of recurrence is probably due to the absence of technical failure among the operated patients. ${ }^{18}$

The compensatory hyperhidrosis observed in this study was distributed in the body in the same way as described in the medical literature, i.e. in the abdomen, back, feet, and gluteal region. In most cases, it is tolerable and does not lead to social disturbances or occupational disability since the patients have been previously informed about this possibility. Patients are inconvenienced only when their symptoms are severe or when they do not receive adequate preoperative information. It is very important that patients always be warned about this possible complication before surgery, because of the irreversibility of the method and the likelihood of compensatory hyperhidrosis.

The key to these good outcomes observed in this study are the resection of the $\mathrm{T} 4$ ganglion and information given to patients. ${ }^{19} \mathrm{~T} 5$ resection is not necessary. ${ }^{11,19}$ For T4 ganglion resection, a complete operation on $\mathrm{T} 4$ is necessary, involving sympathicotomy from the upper margin of the fourth rib to the lower margin of the fifth rib, followed by thermoablation of the chain. ${ }^{20}$ Patient satisfaction at six months follow-up was greater in this group than in the T3-T4 group. ${ }^{18,21,22}$ The high satisfaction in the T4 group increased even more at 12 months follow-up.

Compensatory hyperhidrosis is the most frequent complication of VATS , and it occurs when an ample resection of the sympathetic chain is performed, at a frequency of up to $89 \%$ of cases. ${ }^{21-24}$ In our series, in which resections were carried out at lower levels, we found that $93.5 \%$ of the patients in the T3-T4 group and $57.6 \%$ in the $\mathrm{T} 4$ group experienced this complication after one year; $35.5 \%$ of the T3-T4 patients showed moderate or intense compensatory hyperhidrosis, whereas only one patient (12.5\%) in the T4 group showed moderate compensatory hyperhidrosis. In addition, the T4 group showed no cases of intense compensatory hyperhidrosis. With respect to mild compensatory hyperhidrosis, we observed that between the six-month and one-year follow-up of the T3- 
T4 group, there was an increase in mild cases (from 16 to 18 ) and a decrease in the more serious cases, although the changes were not statistically significant. In contrast, the T4 group showed a decrease in the number of mild cases (from 14 to 13) since many patients started to feel that they were free from these effects.

We did not use any objective measurement of sudoresis because these methods produce only data at a specific point in time. There are no methods capable of measuring hyperhidrosis over an entire day.

Despite the presence of compensatory hyperhidrosis, all the patients of our series reported that the procedure had improved their quality of life. The satisfaction was high in both groups, with no statistical difference between the groups at either one-month or six-month follow-ups.
Long-term follow-up of these two groups may show whether these results persist. In the event of late recurrence of symptoms among patients in the $\mathrm{T} 4$ group, reoperation could be carried out in order to extend the sympathectomy to the $\mathrm{T} 3$ ganglion. ${ }^{25-27}$

\section{CONCLUSION}

We conclude that resection of the T4 ganglion is preferable to resection of the T3 and T4 ganglia together. Despite their equal efficacy for reducing axillary hyperhidrosis, T4 resection leads to a lower rate of compensatory hyperhidrosis.

Compensatory hyperhidrosis in the T4 group tended to decrease over time, which was reflected in the statistically significant improvement in long-term personal satisfaction. ${ }^{28}$

\section{REFERENCES}

1. Glaser DA. The use of botulinum toxins to treat hyperhidrosis and gustatory sweating syndrome. Neurotox Res. 2006;9:173-7.

2. Atkins JL, Butler PE. Hyperhidrosis: A Review of Current Management. Plast Recon Surg. 2002; 110:222-8.

3. Rompel R, Scholz S. Subcutaneous Curettage vs. Injection of Botulinum Toxin A for Treatment of Axillary Hyperhidrosis. J Eur Acad Dermatol Venereol. 2001; 15:207-11.

4. Proebstle TM, Schneiders V, Knop J. Gravimetrically Controlled Efficacy of Subcorial Curettage: A Prospective study for Treatment of Axillary Hyperhidrosis. Dermatol Surg. 2002;28:1022-6.

5. Loureiro MP, Campos JR, Kauffman P, Jatene FB, Weigmann S, Fontana A. Endoscopic lumbar sympathectomy for women: effect on compensatory sweat. Clinics. 2008;63:189-96

6. Munia MA, Wolosker N, Kauffman P, de Campos JR, Puech-Leão P A randomized trial of T3-T4 versus T4 sympathectomy for isolated axillary hyperhidrosis. J Vasc Surg. 2007;45:130-3.

7. de Campos JR, Wolosker N, Takeda FR, Kauffman P, Kuzniec S, et al. The body mass index and level of resection: predictive factors for compensatory sweating after sympathectomy. Clin Auton Res. 2005;15:116-20.

8. de Campos JR, Kauffman P, Werebe Ede C, Andrade Filho LO, Kusniek S, Wolosker N, et al. Quality of life, before and after thoracic sympathectomy: report on 378 operated patients. Ann Thorac Surg. 2003;76:886-91.

9. Wolosker N, Yazbek G, Milanez de Campos JR, Kauffman P, Ishy A, Puech-Leão P. Evaluation of plantar hyperhidrosis in patients undergoing video-assisted thoracoscopic sympathectomy. Clin Auton Res. 2007; 17:172-6. Epub 2007 Jun 12.

10. Lawrence CM, Lonsdale Eccles AA. Selective sweat gland removal with minimal skin excision in the treatment of axillary hyperhidrosis: a retrospective clinical and histological review of 15 patients. $\mathrm{Br} \mathrm{J}$ Dermatol. 2006;155:115-8.

11. Hsu CP, Shia SE, Hsia JY, Chuang CY, Chen CY. Experiences in Thoracoscopic Simpathectomy for Axillary Hyperhidrosis and Osmidrosis : focusing on the extent of sympathectomy. Arch Surg. 2001;136:1115-17.

12. Byrne J, Walsh TN, Hederman WP. Endoscopic Transthoracic Electrocautery of the Simpathetic Chain for Palmar and Axillary Hyperhydrosis. Br J Med. 1990; 771046-9.

13. Rex LO, Drott C, Claes G, Gothberg G,Dalman P. The Boras Experience of Endoscopic Toracic Sympathicotomy for Palmar, Axillary, Facial Hyperhidrosis and Facial Blushing. Eur J Surg. 1998; (suppl)580:23-6.

14. Hsu CP, Chen CY, Hsia JY, Shai SE. Resympathectomy for Palmar and
Axillary Hyperhidrosis. Br J Surg. 1998; 85:1504-5.

15. Gossot D, Debrosse D, Grunenwald D. Endoscopic Thoracic Sympathectomy for Isolated Axillary Hyperhidrosis. Ann Dermatol Venereol. 2000; 127:1065-7.

16. Gossot D, Galetta D, Pascal A, Debrosse D, Caliandro R, Girard P, Stern JB, Grunenwald D.. Long-term Results of Endoscopic Thoracic Sympathectomy for Upper Limb Hyperhidrosis. Ann Thorac Surg. 2003;75:1075-9.

17. Claes G. Indications for Endoscopic Thoracic Sympathectomy. Clin Auton Res. 2003;13(suppl1):1/16-1/19.

18. Yazbek G, Wolosker N, de Campos JR, Kauffman P, Ishy A, Puech-Leao P. Palmar hyperhidrosis--which is the best level of denervation using video-assisted thoracoscopic sympathectomy: T2 or T3 ganglion? J Vasc Surg. 2005;42:281-5.

19. Masters A, Rennie JA. Endoscopic Transthoracic Simpathectomy for Idiopathic Upper Limb Hyperhidrosis. Clin Auton Res. 1992;2:34952.

20. Lin CC \& Wu HH. Endoscopic T4 Sympathetic Block By Clamping ESB4 in Treatment of Hyperhidrosis Palmaris et Axillaris --Experience of 165 Cases. Ann Chir Gynecol. 2001; 90:167-9.

21. Licht PB, \& Pilegaard HK. Severity of Compensatory Sweating after Thoracoscopic Sympathectomy. Ann Thorac Surg. 2004;78:427-31.

22. Licht PB, Jorgensen OD, Ladegaard L, Pilegaard HK. Thoracoscopic sympathectomy for axillary hyperhidrosis: the influence of T4. Ann Thorac Surg. 2005;80:455-9.

23. Cameron AE. Specific Complications and Mortality of Endoscopic Thoracic Sympathectomy. Clin Auton Res. 2003;13:31-5.

24. Neumayer C, Zacherl J, Holak G, Fugger R, Jakesz R, Herbst F, et al. Limited Endoscopic Thoracic Simpathectomy Block for Hyperhidrosis of the Upper Limb: Reduction of Compensatory Sweating by Clipping T4. Surg Endosc. 2004; 18:152-6.

25. Lin TS. Endoscopic Clipping in Video-assisted Thoracoscopic Sympathectomy Blockade for Axillary Hyperhidrosis. An Analysis of 26 Cases. Surg Endosc. 2001;15:126-8.

26. Dewey TM, Herbert MA, Hill SL, Prince SL, Mack MJ. One-Year Follow-Up After Thoracoscopic sympathectomy for Hyperhidrosis: Outcomes and Consequences. Ann Thorac Surg. 2006;81:1227-32; discussion 1232-3.

27. Wolosker N, Yazbek G, Ishy A, de Campos JR, Kauffman P, Puech-Leão P. Is sympathectomy at $\mathrm{t} 4$ level better than at $\mathrm{t} 3$ level for treating palmar hyperhidrosis? J Laparoendosc Adv Surg Tech A. 2008;18:102-6.

28. Milanez de Campos JR, Kauffman P, Wolosker N, Munia MA, de Campos Werebe E, Andrade Filho LO, et al. Axillary hyperhidrosis: T3/T4 versus T4 thoracic sympathectomy in a series of 276 cases. J Laparoendosc Adv Surg Tech A. 2006;16:598-603. 